\title{
Um Curso Mooc de Pensamento Computacional contextualizado no Cotidiano Feminino
}

\author{
Vânia Silvares Marquiori' ${ }^{1}$, Márcia Gonçalves de Oliveira' ${ }^{1}$ \\ ${ }^{1}$ Instituto Federal de Educação, Ciência e Tecnologia do Espírito Santo \\ vania.ifes@gmail.com, clickmarcia@gmail.com
}

\begin{abstract}
This article presents a course entitled Mooc de Lovelace: Computational Thinking in feminine's Everyday, created with the objective of attracting women to know the fundamentals of Computer Science. The results presented the female audience as the participant majority and certificate, pointing out that the use of everyday situations emphasizing the female audience can contribute to the fight against gender inequalities in the world of work.
\end{abstract}

Resumo. Este artigo apresenta um curso intitulado Mooc de Lovelace: Pensamento Computacional no Cotidiano Feminino, criado com o objetivo de atrair mulheres para conhecer os fundamentos da Ciência da Computação. Os resultados apresentaram o público feminino como maioria participante $e$ certificado, apontando que a utilização de situações cotidianas enfatizando o público feminino pode contribuir para o combate às desigualdades de gênero no mundo do trabalho.

\section{Introdução}

O avanço tecnológico tem sido responsável por alterações rápidas e constantes nos mais distintos segmentos sociais, entre eles destacam-se os setores produtivos, que demandam cada vez mais profissionais capazes de solucionar novas demandas, muito comumente ligadas ao progresso tecnológico e seu constante crescimento[Jimenez e Fernandez 2016; OIT 2016].

Nesse contexto, estreita-se o olhar para o público feminino no mundo do trabalho em meio ao progresso tecnológico, que ainda hoje é majoritariamente excluído, tanto no processo formativo [Nunes 2019], quanto no desempenho de atividades decorrentes do avanço tecnológico [OIT 2016]. Diante disso, percebe-se que ações formativas que objetivem a popularização de conhecimentos básicos de computação tem sido uma necessidade real de nossa sociedade. E nesse contexto, as redes têm permitido o desenvolvimento de formações que vencem diversas barreiras, como as geográficas, por exemplo, com os cursos no formato MOOC ( Massive Open Online Course - Curso Massivo, Aberto e Online), termo cunhado por George Siemens [MacAuley 2010].

Assim, nesta pesquisa, o formato Mooc é utilizado no contexto da Educação Profissional e Tecnológica (EPT), que é aquela que conduz seus processos formativos aliada às dimensões do trabalho, da ciência e da tecnologia [Brasil, 1996], para ambientar o curso Mooc de Lovelace: Pensamento Computacional no Cotidiano Feminino, com atividades ligadas ao contexto feminino, utilizadas como âncora para inserir, por meio da prática, o conceito de Pensamento Computacional, considerando o objetivo e contribuição do curso, de atrair as mulheres para conhecerem os fundamentos da Ciência da Computação, e quem sabe resgatar o interesse desse público pela área. 
De modo que o presente trabalho encontra-se dividido em algumas seções, além desta, sendo: a segunda seção com a apresentação da revisão de literatura, a terceira, abordando os trabalhos relacionados, a quarta com a metodologia e por fim, as considerações finais.

\section{Revisão de Literatura}

O Pensamento Computacional (PC) pode ser concebido como uma ferramenta mental [Wing 2006] que permite aos seres humanos apropriar soluções para problemas de forma que tais soluções possam ser executadas por máquinas [Liukas 2019], sendo, portanto, uma maneira de as pessoas pensarem soluções. Essa ferramenta mental é composta por quatro pilares, cada um com uma finalidade facilitadora no processo de resolução de determinado problema, conforme apresentado no Quadro 1, e possui variadas possibilidades de utilização, tanto na vida profissional quanto na vida pessoal.

De acordo com Brackmann [2017] e Liukas [2019] os pilares do PC são Abstração, que elenca pontos essenciais, descartando as informações supérfluas, para facilitar a solução de um problema. Algoritmo que consiste em uma sequência de passos finita, evidenciando passos em sequência lógica que levam à solução de um problema. Decomposição que transforma um problema em problemas ou partes menores, facilitando a solução. E o Reconhecimento de padrões, em que características utilizadas para solucionar um problema, são utilizadas na solução de problemas similares.

Sendo o PC tomado aqui como uma forma de disseminar conhecimentos básicos de Ciência da Computação, com vistas a despertar o interesse de mais pessoas, principalmente mulheres, partindo da falta de profissionais nas áreas tecnológicas e das altas taxas de evasão, mais acentuada quando se trata do público feminino, conforme demonstram as Tabelas 1 e 2, de acordo com dados encontrados em Nunes [2019].

Tabela 1 -Matriculados

\begin{tabular}{|c|c|c|c|}
\hline Ano & Mulheres & Homens & Total \\
\hline 2015 & 28245 & 170793 & 199038 \\
\hline 2016 & 39332 & 238873 & 278205 \\
\hline 2017 & 40931 & 247604 & 288535 \\
\hline 2018 & 48570 & 307420 & 355990 \\
\hline 2019 & 49734 & 306392 & 356126 \\
\hline
\end{tabular}

E, muito embora, as mulheres já tenham sido pioneiras em áreas de progresso, como é o caso do ramo da tecnologia, esse apagamento feminino da história indica que a área tecnológica carece de ações que atraiam mais mulheres para a área.

\section{Trabalhos relacionados}

O trabalho de Oliveira et. al. [ 2018], que expõe um projeto piloto de letramento em programação para meninas, com foco no público de meninas surdas, no formato Mooc. Neste trabalho percebe-se a sensibilidade com um público excluído, sendo importante destacar que 
a disseminação dos conhecimentos tecnológicos é uma necessidade para muitos públicos, tendo em vista que, para vencer as desigualdades, essa popularização também precisa alcançar as minorias excluídas dentro de cada segmento da sociedade.

Este trabalho se assemelha a essa pesquisa quanto à popularização dos conhecimentos referentes aos fundamentos da Ciência da Computação, mas diferencia-se por possibilitar a interação de mulheres, de diferentes contextos sociais, dentro de um curso Mooc pensado e organizado para mulheres, levando os participantes a refletir sobre a própria necessidade das mulheres aprimorarem seus conhecimentos e se posicionar na Sociedade da Informação.

\section{Metodologia}

O curso Mooc foi desenvolvido e avaliado com base no modelo ADDIEM, modelo adaptado pelo Centro de de Referência em Formação e em Educação a Distância - Cefor, tomando como base o modelo ADDIE. O ADDIE (Analyze, Design, Develop, Implement and Evaluate - Análise, Projeto, Desenvolvimento, Implementação e Avaliação), é um modelo composto de cinco fases, utilizado para o planejamento de ações de ensino [ Munhoz 2016].

O ADDIEM segue os mesmos princípios do ADDIE, diferenciando-se pelas características exigidas na formatação de um Mooc, que deve ser produzido de forma clara evitando dúvidas, considerando que nesse formato de curso não há tutoria, além de ter mais uma fase, que identifica essa ação como sendo um Mooc [Battestin e Santos 2019].

Dessa maneira foi concebido, implementado e avaliado o Mooc de Lovelace: Pensamento Computacional no Cotidiano Feminino. O curso foi composto por oficinas, inspiradas na metodologia ativa $A B P$, que é uma das metodologias ativas que parte de problemas simples para engajar alunos na construção de seus próprios conhecimentos [Filatro e Cavalcanti, 2018], e aplicadas conforme o Quadro 2.

Quadro 1 - Oficinas de Pensamento Computacional

\begin{tabular}{|c|c|}
\hline Oficinas & Estratégia de Letramento \\
\hline $\begin{array}{l}\text { PC } \\
\text { Confeitado }\end{array}$ & $\begin{array}{l}\text { Nesta oficina foi apresentado um vídeo contendo a execução de uma receita, e os participantes foram convidados a pesquisar } \\
\text { sua própria receita(algoritmo), e decompor esta receita em itens de: entrada, processamento e saída. Depois, a atividade foi } \\
\text { compartilhada pelos participantes por meio de fórum com os demais participantes. }\end{array}$ \\
\hline $\begin{array}{c}\text { PC } \\
\text { Maquiado }\end{array}$ & $\begin{array}{l}\text { Para esta oficina foi apresentado um vídeo contendo um tutorial de maquiagem, e a atividade consistia em cada participante } \\
\text { eleger um dos passos da maquiagem, praticar a decomposição, transformando esse passo em um novo algoritmo. }\end{array}$ \\
\hline $\begin{array}{c}\text { PC } \\
\text { Endereçado }\end{array}$ & $\begin{array}{l}\text { Para o desenvolvimento desta oficina foi preparado um tutorial de como traçar uma rota no aplicativo Google Maps, e os } \\
\text { participantes eram convidados a traçar uma rota e compartilhar via fórum dentro do curso. Nessa oficina utilizava-se o } \\
\text { algoritmo, percebia-se a abstração do mundo real por meio do mapa e chegava-se à decomposição de um caminho em } \\
\text { passos. Neste tópico também continha outra atividade, possibilitada pela ferramenta Padlet, onde os participantes eram } \\
\text { convidados a compartilhar um algoritmo de seu cotidiano. }\end{array}$ \\
\hline $\begin{array}{c}\mathrm{PC} \\
\text { Divertido }\end{array}$ & $\begin{array}{l}\text { Esta última oficina contava com uma atividade de caráter desplugado chamada "Atravessando o Rio". Nela o participante tinha } \\
\text { acesso às regras do jogo e o objetivo era alcançar o algoritmo (passo a passo) mais eficaz, ou seja, com o menor número de } \\
\text { passos possível, para atravessar os personagens de um lado do rio para outro, utilizando o reconhecimento de padrões. } \\
\text { E para finalizar tinha o último fórum que tinha como objetivo proporcionar a participação em outra plataforma, e chamava-se } \\
\text { Desafio Code.org. Nela o participante executava uma atividade nessa plataforma e compartilhava por meio do fórum proposto } \\
\text { Sendo essa a atividade mais rica em pilares, considerando que os participantes deveriam seguir instruções para praticar uma } \\
\text { outra atividade, que eles mesmo escolheram. }\end{array}$ \\
\hline
\end{tabular}

O curso foi liberado para acesso ao público em 27 de novembro de 2020 e foi divulgado através da aula inaugural ${ }^{1}$, exibida pelo canal do Cefor no Youtube, no dia 02 de dezembro de 2020. O público alvo foram mulheres e os pré-requisitos para participação no

\footnotetext{
${ }^{1}$ Aula inaugural do curso: https://www.youtube.com/watch?v=a2z IcxCVUs.
} 
curso foram: ter concluído ou estar cursando a partir do ensino fundamental II e ter conhecimentos básicos de navegação na Internet.

A faixa etária dos participantes foi de 19 anos até participantes com idade superior a 56 anos. A escolaridade esteve compreendida de Ensino Médio Completo a Pós Graduação. E por fim, informa-se que o curso contou com participantes dos seguintes estados brasileiros: DF, ES, MS, PA, SP, SC, RN, RS e RJ. Inicialmente a pesquisa buscou verificar os conhecimentos acerca de PC pelos participantes do curso através de um questionário inicial antes do curso. Dos respondentes, identificou-se que nem todos conheciam o termo, no entanto, após explanação dos conteúdos, as atividades propostas foram adequadamente executadas.

Considerando o caráter autônomo do curso Mooc, até o momento ainda não é possível mensurar os dados de evasão, tendo em vista que o curso ainda não se findou. Assim, os dados parciais mostram que até a data de 16 de abril de 2021, data de produção desse artigo, o curso contava com 85 inscritos, dos quais, apenas 06 eram do sexo masculino, indicando que mais de $90 \%$ dos inscritos eram do sexo feminino. Dos 16 inscritos que finalizaram o curso, apenas 1 era do sexo masculino.

Ao final, os participantes foram novamente ouvidos acerca da importância do PC e da contribuição das atividades para compreensão do tema, e as respostas apontam que as atividades contribuíram para a compreensão do tema. Ao serem perguntados sobre a importância de incentivar mulheres para a área, os participantes também afirmaram que a iniciativa é relevante.

Já a pesquisa de satisfação do curso, ouviu os 16 concluintes, em relação aos materiais disponibilizados e o curso de maneira geral. Uma das perguntas buscava saber como o participante avaliava o curso, com as seguintes possibilidades de resposta: Muito bom, bom, regular, ruim e muito ruim, e 100\% dos participantes avaliaram o curso como muito bom.

Quanto à metodologia do curso, 93,75\% dos participantes informaram que os conteúdos estavam adequados e facilitaram a aprendizagem, ao passo que 6,25\% consideraram que as atividades não estavam adequadas ao conteúdo do curso. Em relação aos vídeos disponibilizados, $87,5 \%$ consideraram os vídeos de fácil compreensão e em profundidade adequada, enquanto $12,5 \%$ gostariam de vídeos mais detalhados. Os textos foram considerados adequados por $81,25 \%$, enquanto $18,75 \%$ gostariam de textos mais detalhados. Quanto a recomendação do curso, numa escala de zero a 10, onde 10 representa totalmente recomendado e zero não recomendado, $81,25 \%$ afirmaram que o curso é totalmente recomendável, assinalando a resposta 10 , enquanto os outros $18,75 \%$ assinalaram a resposta 9, o que também torna o curso recomendável na visão dos últimos.

Dessa forma, percebe-se que mesmo sendo um curso que não envolveu a programação efetiva de computadores, a ação contribuiu para utilização dos conceitos de Computação sem a necessidade de modificar as engrenagens de um computador, apenas utilizando a rede como meio de acessar esse conhecimento. Fato que indica a potencialidade desse formato de curso na popularização da linguagem de programação, tendo em vista que as atividades podem ser adaptadas para o formato desplugado.

Outro ponto que cabe destacar, é que essa pesquisa gerou um Produto Educacional, contendo o passo a passo para a construção de oficinas que tenham como objetivo disseminar o PC, ou utilizá-lo como facilitador no ensino para interessados em produzir oficinas facilitadas por essa ferramenta mental. Este produto encontra-se disponível para acesso em: 
https://docs.google.com/document/d/1tI5husSbWSB dI8eQfiM10 dku 2vzcbWcUXosQV1V 8/edit?usp=sharing.

\section{Considerações finais}

Como principais resultados, aponta-se que a popularização dos conhecimentos de $P C$ são possíveis por meio de cursos Mooc, pelo seu alcance e caráter democrático, tendo em vista que não há processo seletivo, e que o assunto é levado para diversas realidades e localidades. Destaca-se também que a utilização do contexto socialmente marcado como feminino, utilizado para ancorar os conhecimentos de Computação mostraram-se relevantes na chamada do público feminino para essa ação formativa. Evidenciando que ações que levam em conta a trajetória feminina marcada por segregação em razão do gênero, devem ser consideradas para entender a necessidade de conceber estratégias que atraiam o público feminino de forma leve e sem estranhamentos.

Ademais, percebendo-se a necessidade de explorar ainda mais o tema, com o olhar voltado para outros públicos, como trabalhos futuros, a intenção é produzir conteúdos acerca do $P C$ para educadores, tendo em vista a possibilidade de alcance do PC por meio de educadores, que lidam com diversos públicos, que também dependem desses conhecimentos para atuar nessa nova sociedade.

\section{Referências}

Battestin, V. Santos, P.S. (2019). Modelo ADDIEM - processo de criação de cursos Mooc. Vitória. Disponível em: Modelo ADDIEM.docx. Acesso em 22 fev 2021.

Brackmann, C. P.(2017). Desenvolvimento do pensamento computacional através de atividades desplugadas na educação básica. Porto Alegre.

Brasil(1996). Lei n ${ }^{\circ}$ 9.394, de 20 de dezembro de 1996. Estabelece as diretrizes e bases da educação nacional. Disponível em: L9394. Acesso em: 24 dez. 2020.

Filatro, A. Cavalcanti, C.C.(2018) Metodologias Inov-Ativas na educação presencial, a distância e corporativa. 1.ed. São Paulo: Saraiva Educação.

Jiménez, R.G.P. Fernández, C. J. (2016). La brecha de género en la educación tecnológica. Ensaio: Avaliação e Políticas Públicas em Educação, v. 24, n. 92, p. 743-771.

Liukas, L. (2019). Olá, Ruby: uma aventura pela programação. Tradução: Stephanie C. L. Fernandes. São Paulo: Companhia das Letras.

Macauley, A., Stewart, B., Siemens, G., and Cormier, D. (2010) The MOOC model for digital practice. Social Sciences and Humanities Research Council, Knowledge Synthesis Grant on the Digital Economy.

Munhoz, A. S.(2016). MOOCS: Produção de conteúdos educacionais.São Paulo: Saraiva.

Nunes, D. J. (2019). Educação Superior em Computação, Estatísticas 2019. Sociedade Brasileira de Computação. Disponível em: https://www.sbc.org.br/documentos-da-sbc/summary/133-estatisticas/1354-educacao-supe rior-em-computacao-estatisticas-2019. Acesso em 09 mai 2021.

OIT. (2016). Mulheres no trabalho: tendências 2016. Genebra: Organização Internacional do Trabalho.

Wing, J. M. (2006). Computational thinking.Communications of the ACM, 49(3):33-35. 